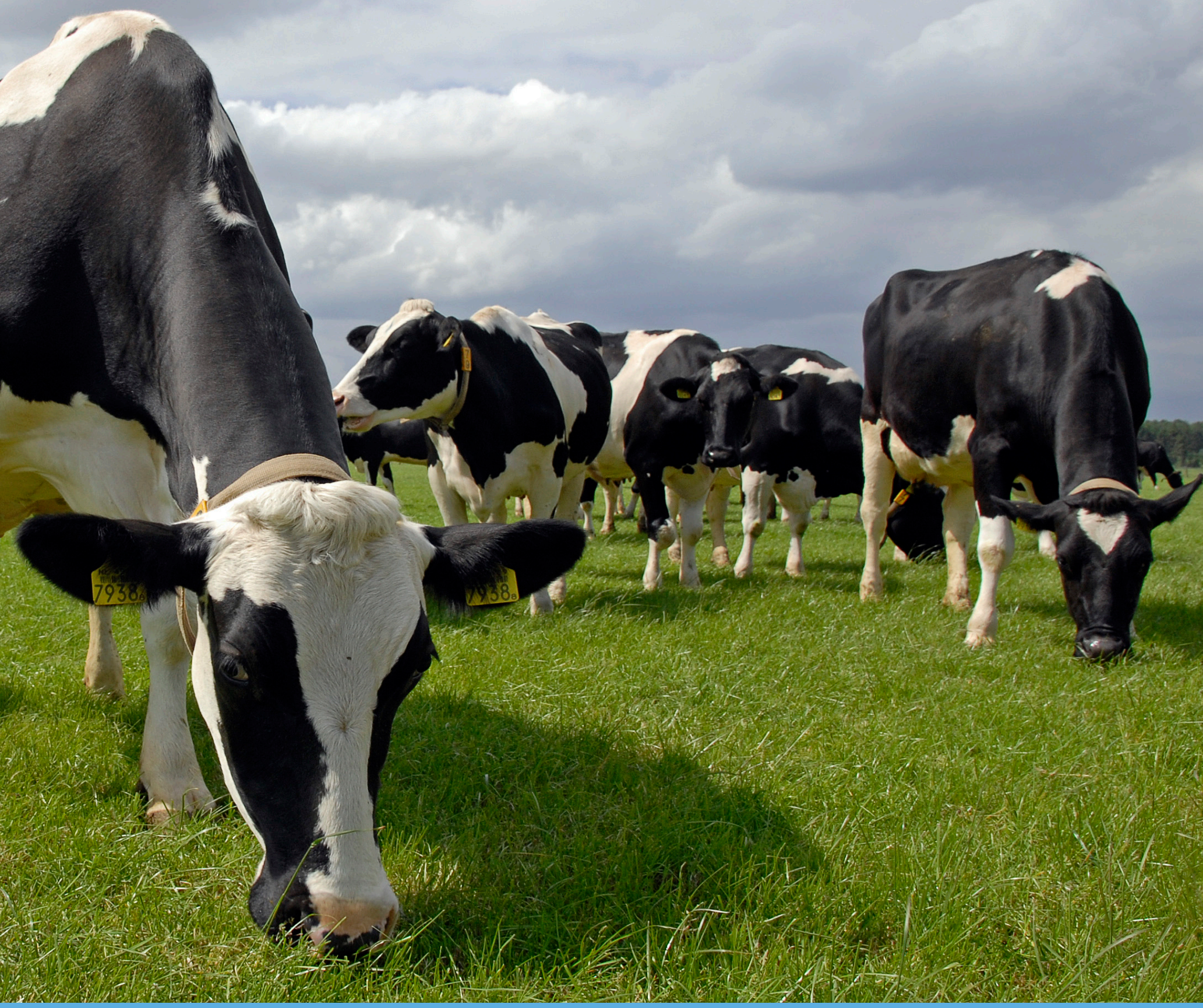

Rassenbericht Grasland 2019 


\section{Rassenbericht Grasland 2019}

Jan Rinze van der Schoot, Henk Schilder

Het Cultuur- en Gebruikswaarde Onderzoek voedergrassen is uitgevoerd door Wageningen Livestock Research in opdracht van en gefinancierd door Plantum.

Wageningen Livestock Research

Wageningen, november 2019

Wageningen Livestock Research

Rapport 1209 
Schoot, J.R. van der, Schilder, H. Rassenbericht Grasland 2019; Wageningen, Wageningen Livestock Research, Rapport 1209.

Samenvatting NL

Rapportage van proefveldresultaten van het rassenonderzoek aan Engels raaigras in de periode 20112018.

Dit rapport is gratis te downloaden op https://doi.org/10.18174/504634 of op www.wur.nl/livestock-research (onder Wageningen Livestock Research publicaties).

(C) 2019 Wageningen Livestock Research

Postbus 338, 6700 AH Wageningen, T 03174839 53, E info.livestockresearch@wur.nl, www.wur.nl/livestock-research. Wageningen Livestock Research is onderdeel van Wageningen University \& Research.

Wageningen Livestock Research aanvaardt geen aansprakelijkheid voor eventuele schade voortvloeiend uit het gebruik van de resultaten van dit onderzoek of de toepassing van de adviezen.

Alle rechten voorbehouden. Niets uit deze uitgave mag worden vermenigvuldigd en/of openbaar gemaakt worden door middel van druk, fotokopie, microfilm of op welke wijze dan ook zonder voorafgaande toestemming van de uitgever of auteur.

Wageningen Livestock Research is NEN-EN-ISO 9001:2015 gecertificeerd. Op al onze onderzoeksopdrachten zijn de Algemene Voorwaarden van de Animal Sciences Group van toepassing. Deze zijn gedeponeerd bij de Arrondissementsrechtbank Zwolle. 


\section{Inleiding}

Dit Rassenbericht Grasland 2019 bevat de nieuwste resultaten van het Cultuur- en Gebruikswaarde Onderzoek (CGO) van Engels raaigras. In het CGO worden rassen van voedergrassen en witte klaver getest op hun landbouwkundige waarde voor de veehouder. Bij goede resultaten komen de rassen op de Aanbevelende Rassenlijst. Voor grasland zijn vooral de eigenschappen standvastigheid, ziekteresistentie (zoals resistentie tegen kroonroest bij Engels raaigras), wintervastheid en drogestofopbrengst belangrijk. De eigenschappen worden beoordeeld op beweidings- en maaiproefvelden, waar de nieuwe rassen samen met de bestaande rassenlijstrassen worden uitgezaaid en onderzocht. 


\section{Resultaten}

Weergegeven zijn de proefveldresultaten van het CGO voor Engels raaigras laat en middentijds doorschietend van de afgelopen jaren. Voor de meeste eigenschappen en de opbrengsten hebben de gegevens betrekking op het gemiddelde van de resultaten verkregen in de periode $2011 \mathrm{t} / \mathrm{m} 2018$. Vermeld zijn de rassenlijstrassen van de Aanbevelende Rassenlijst Veehouderij 2020 en de rassen in onderzoek van de uitzaaijaren 2015 en 2016. De rassen van 2015 zijn reeds beoordeeld voor opname op Rassenlijst 2020.

In dit Rassenbericht Grasland 2019 zijn van Engels raaigras de nieuwe, aanbevolen rassen van Rassenlijst $\mathbf{2 0 2 0}$ vermeld met hun waarderingscijfers. De opname en volgorde is gebaseerd op het advies en het persbericht van de Commissie Samenstelling Aanbevelende Rassenlijst (CSAR).

Voor opname is ook inschrijving in het Nederlands Rassenregister en/of EU-verkeerstoelating nodig. De rassen van 2016 worden volgend jaar beoordeeld, omdat het onderzoek nog niet is afgerond. Voor de overige (gras)soorten die in de Aanbevelende Rassenlijst staan vermeld, zijn geen nieuwe gegevens verkregen. Voor meer informatie over grassoorten, graslandmengsels en raseigenschappen wordt verwezen naar de Aanbevelende Rassenlijst Veehouderij 2020, te vinden op https://rassenlijst.info/. Ook de eigenschappen van de rassenlijstrassen van de andere grassoorten en typen (Engels raaigras vroeg doorschietend, gekruist raaigras, Italiaans raaigras, timothee en beemdlangbloem) en van witte klaver staan hierin vermeld. 


\section{Toelichting op de tabellen}

Het jaartal achter de rasnaam geeft het eerste jaar van uitzaai en onderzoek aan.

( ) betekent: gegevens zijn gebaseerd op weinig waarnemingen.

- betekent: geen of onvoldoende waarnemingen.

Een hoog cijfer betekent een gunstige waardering van de betrokken eigenschap.

De drogestofopbrengst is per soort of type weergegeven in verhoudingsgetallen. Deze zijn gebaseerd op het gemiddelde van de A- en N-rassen van de desbetreffende soort of het type van de Aanbevelende Rassenlijst 2019. Naast de gemiddelde totale jaaropbrengst van de maaiproeven en de beweidingsproeven is ook de opbrengst van de eerste en eerste plus tweede snede vermeld. Het opbrengstniveau van de eerste snede geeft informatie over de voorjaarsgroei in relatie tot de doorschietdatum. De gezamenlijk opbrengst van de eerste plus tweede snede geeft informatie over het opbrengstniveau van het veelal kwalitatief hoogwaardige gras in het voorjaar.

$\mathrm{Bij} 100=\ldots$ ton ds/ha is het opbrengstniveau van de rassenproeven vermeld. De opbrengstniveau's van de beweidingsproeven en de maaiproeven zijn niet direct vergelijkbaar door verschillen in beproevingslocaties en management.

De waarderingscijfers en opbrengstgegevens zijn alleen binnen de soort of het type direct vergelijkbaar. Door verschillen in beproevingsperiode, -omvang en -methode kunnen gegevens niet zondermeer gebruikt worden voor een directe onderlinge vergelijking van typen en soorten.

Afkortingen van namen van kwekers of houders/aanvragers kwekersrecht.

AFBI : Agri-Food and Biosciences Institute, Loughgall, Noord Ierland

Bar : Barenbrug Holland B.V., Nijmegen

DLF : DLF A/S, Roskilde, Denemarken

DSV : DSV AG, Lippstadt, Duitsland

IBER : Inst. of Biological Environmental \& Rural Sciences, Aberystwyth, Groot Brittannië

ILVO : ILVO - Plant, Melle, België

RAGT : RAGT 2n S.A.S., Rodez, Frankrijk

SdF : Semences de France, Orchies, Frankrijk

Afkortingen van namen van Nederlandse vertegenwoordigers.

$\begin{array}{ll}\text { Bar } & \text { : Barenbrug Holland B.V., Nijmegen } \\ \text { DLF } & \text { : DLF B.V., Kapelle } \\ \text { DSV } & \text { : DSV zaden Nederland B.V., Gennep } \\ \text { Joo } & \text { : Joordens Zaden B.V., Kessel } \\ \text { Lim } & \text { : Limagrain Nederland B.V., Rilland } \\ \text { VDS } & \text { : Vandinter Semo BV, Scheemda }\end{array}$




\section{ENGELS RAAIGRAS LAAT DOORSCHIETEND}

Overzicht van de raseigenschappen

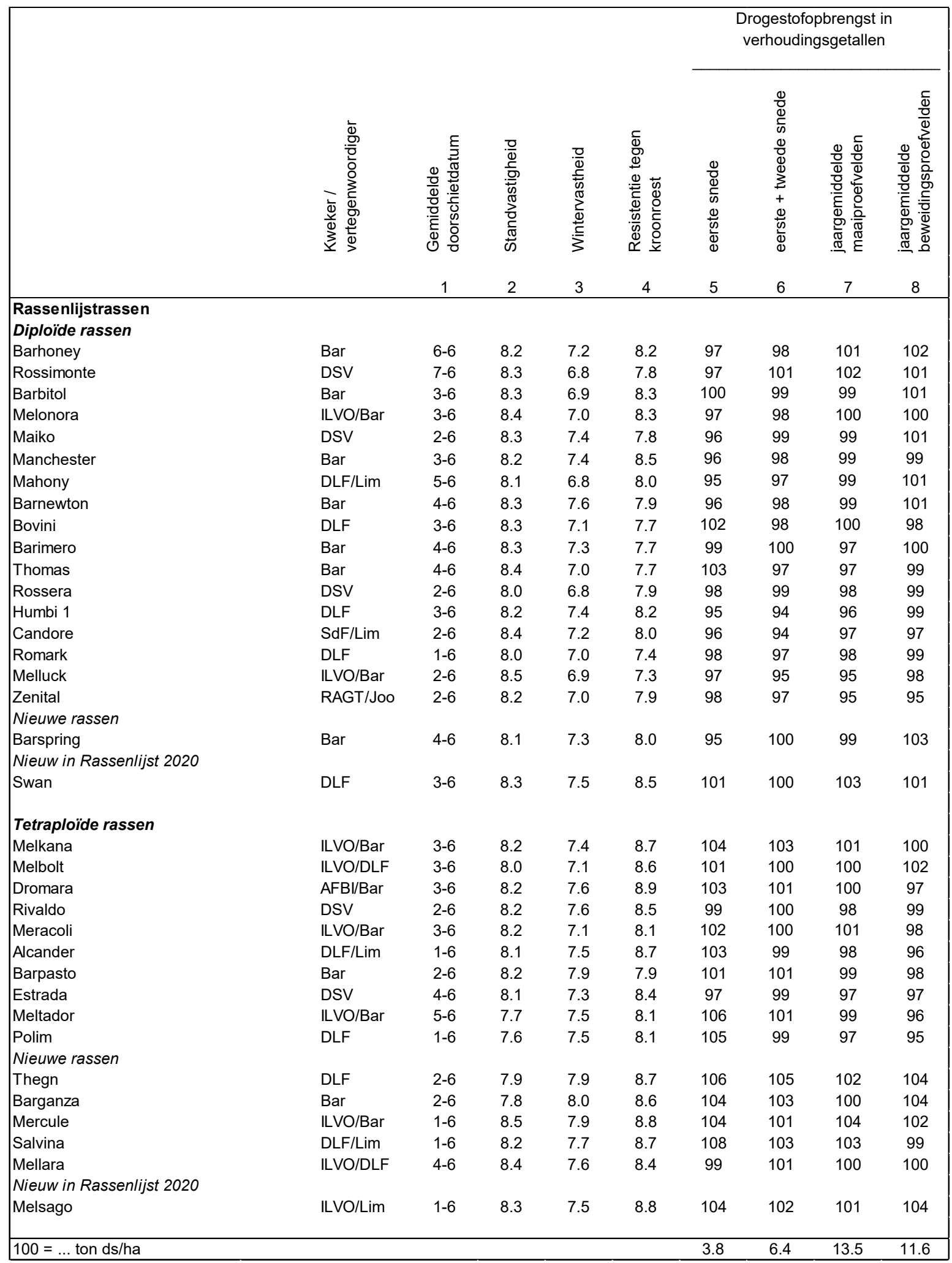




\section{Vervolg ENGELS RAAIGRAS LAAT DOORSCHIETEND}

Overzicht van de raseigenschappen

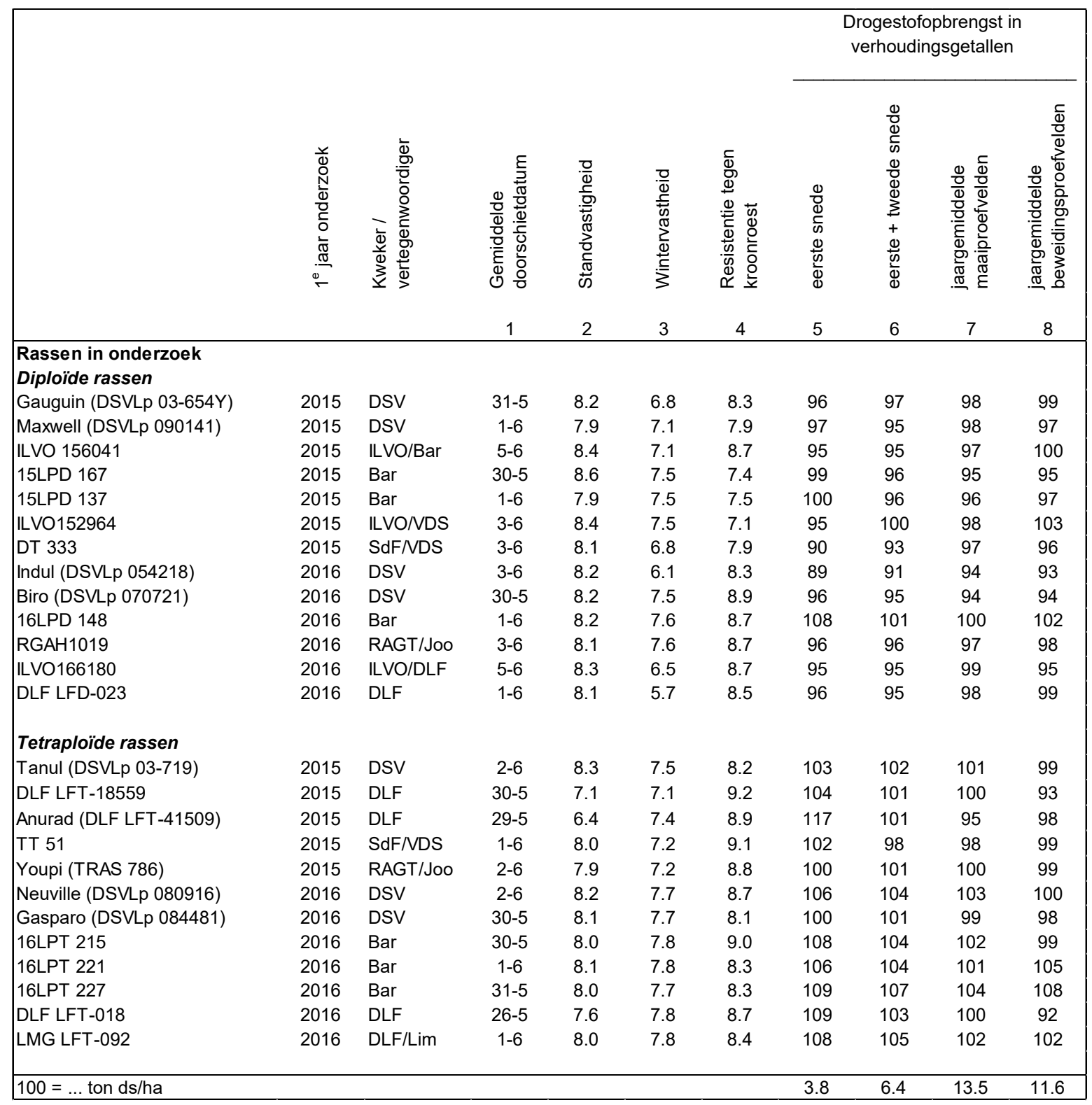




\section{ENGELS RAAIGRAS MIDDENTIJDS}

Overzicht van de raseigenschappen

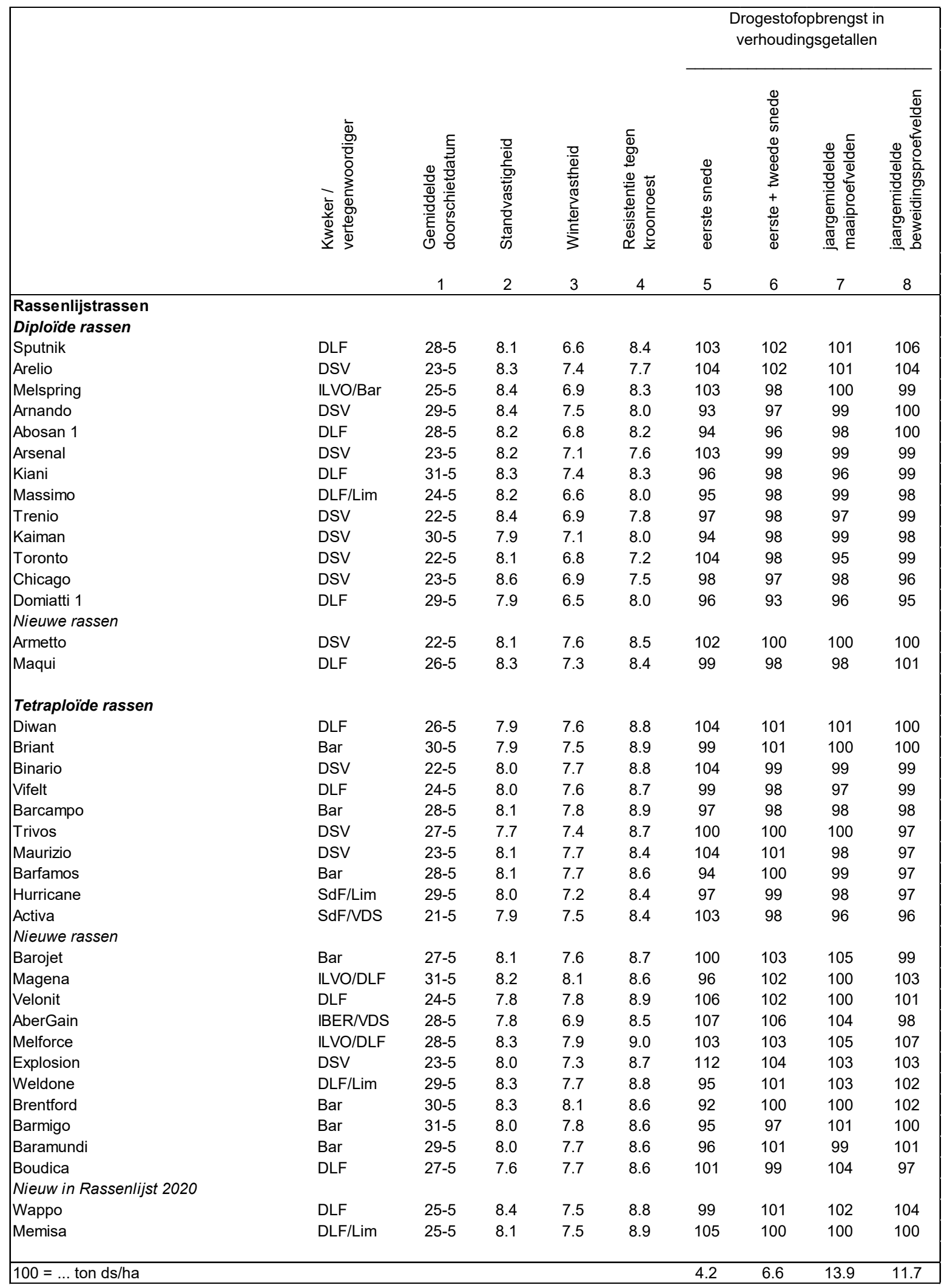




\section{Vervolg ENGELS RAAIGRAS MIDDENTIJDS}

Overzicht van de raseigenschappen

\begin{tabular}{|c|c|c|c|c|c|c|c|c|c|c|}
\hline & & & & & & & & $\begin{array}{l}\text { gesto } \\
\text { rhoud }\end{array}$ & $\begin{array}{l}\text { brengst } \\
\text { sgetalle }\end{array}$ & \\
\hline & 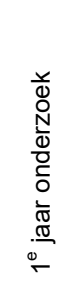 & 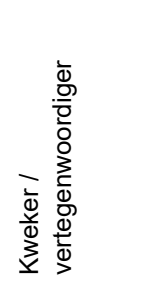 & 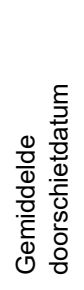 & 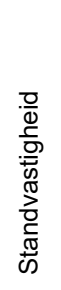 & 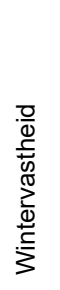 & 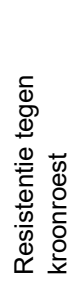 & 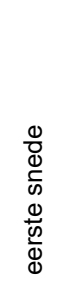 & 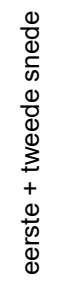 & 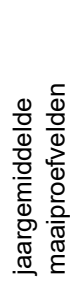 & 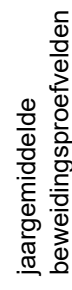 \\
\hline & & & 1 & 2 & 3 & 4 & 5 & 6 & 7 & 8 \\
\hline $\begin{array}{l}\text { Rassen in onderzoek } \\
\text { Diploïde rassen }\end{array}$ & & & & & & & & & & \\
\hline Flavinus (DSVLp 072025) & 2015 & DSV & $28-5$ & 7.8 & 7.3 & 8.1 & 101 & 100 & 100 & 97 \\
\hline Iberico (DSVLp 04-738) & 2015 & DSV & $24-5$ & 8.4 & 7.4 & 8.4 & 91 & 92 & 92 & 92 \\
\hline 15LPD 129 & 2015 & Bar & $25-5$ & 8.4 & 7.3 & 8.6 & 100 & 98 & 98 & 98 \\
\hline 15LPD 121 & 2015 & Bar & $25-5$ & 7.9 & 7.4 & 8.2 & 102 & 100 & 98 & 101 \\
\hline 15LPD 110 & 2015 & Bar & $26-5$ & 8.1 & 7.3 & 8.4 & 97 & 96 & 96 & 101 \\
\hline DLF LFD-21534 & 2015 & DLF & $24-5$ & 8.3 & 7.2 & 8.3 & 92 & 95 & 95 & 97 \\
\hline Hannes (DLF LFD-21686) & 2015 & DLF & $26-5$ & 7.6 & 7.4 & 8.3 & 99 & 98 & 98 & 100 \\
\hline Ilea (ILVO156035) & 2015 & ILVO/DLF & $30-5$ & 8.1 & 6.8 & 8.7 & 84 & 94 & 97 & 97 \\
\hline Anterio (LMG LFD-21591) & 2015 & DLF/Lim & $26-5$ & 7.9 & 6.9 & 8.4 & 95 & 98 & 97 & 96 \\
\hline Vilag (DSVLp 080662) & 2016 & DSV & $23-5$ & 7.9 & 6.9 & 8.9 & 98 & 96 & 100 & 97 \\
\hline Mabello (DSVLp 080672) & 2016 & DSV & $28-5$ & 8.3 & 6.5 & 8.7 & 92 & 96 & 98 & 95 \\
\hline Barmazing (16LPD 101) & 2016 & Bar & $23-5$ & 8.2 & 7.4 & 8.7 & 107 & 102 & 104 & 108 \\
\hline Barriot (16LPD 112) & 2016 & Bar & $22-5$ & 7.8 & 7.1 & 8.6 & 110 & 98 & 100 & 101 \\
\hline RGAH1090 & 2016 & RAGT/Joo & $23-5$ & 8.1 & 6.0 & 8.6 & 103 & 100 & 103 & 97 \\
\hline DLF LFD-4304 & 2016 & DLF & $30-5$ & 8.1 & 5.8 & 8.4 & 94 & 95 & 100 & 93 \\
\hline DLF LFD-18557 & 2016 & DLF & $21-5$ & 7.9 & 6.4 & 8.6 & 99 & 99 & 101 & 99 \\
\hline Pirate (LMG LFD-4337) & 2016 & DLF/Lim & $27-5$ & 8.0 & 7.2 & 8.1 & 91 & 93 & 95 & 90 \\
\hline AberBann (Ba14124) & 2016 & IBER/VDS & $2-6$ & 8.0 & 4.8 & 8.4 & 88 & 95 & 100 & 95 \\
\hline Tetraploïde rassen & & & & & & & & & & \\
\hline Botond (DSVLp 070769) & 2015 & DSV & $22-5$ & 7.8 & 7.5 & 8.3 & 108 & 103 & 104 & 98 \\
\hline 15LPT 240 & 2015 & Bar & $26-5$ & 8.0 & 7.5 & 8.6 & 104 & 101 & 99 & 99 \\
\hline 15LPT 203 & 2015 & Bar & $27-5$ & 8.3 & 7.5 & 8.6 & 101 & 101 & 101 & 101 \\
\hline 15LPT 201 & 2015 & Bar & $24-5$ & 7.6 & 7.5 & 8.4 & 100 & 100 & 97 & 96 \\
\hline Yucatan (LMG LFT-74922) & 2015 & DLF/Lim & $28-5$ & 7.6 & 7.4 & 8.7 & 100 & 99 & 97 & 96 \\
\hline Convey (DLF LFT-74918) & 2015 & DLF & $26-5$ & 7.6 & 7.5 & 8.4 & 102 & 100 & 99 & 99 \\
\hline DSVLp 060553 & 2016 & DSV & $29-5$ & 8.2 & 7.1 & 8.8 & 97 & 100 & 100 & 97 \\
\hline 16LPT 206 & 2016 & Bar & $27-5$ & 7.8 & 7.4 & 8.5 & 105 & 104 & 101 & 105 \\
\hline 16LPT 213 & 2016 & Bar & $25-5$ & 7.8 & 7.4 & 8.9 & 109 & 103 & 100 & 104 \\
\hline 16LPT 234 & 2016 & Bar & $30-5$ & 8.1 & 7.3 & 8.1 & 99 & 100 & 99 & 102 \\
\hline Barleffe (16LPT 9203) & 2016 & Bar & $28-5$ & 7.8 & 7.4 & 8.6 & 102 & 103 & 100 & 109 \\
\hline Bijou (TRAH771) & 2016 & RAGT/Joo & $27-5$ & 7.7 & 7.2 & 8.8 & 96 & 99 & 97 & 93 \\
\hline ILVO166177 & 2016 & ILVO/DLF & $29-5$ & 8.4 & 7.4 & 8.7 & 97 & 100 & 100 & 106 \\
\hline DLF LFT-9513 & 2016 & DLF & $24-5$ & 7.8 & 7.3 & 9.0 & 95 & 97 & 98 & 104 \\
\hline LMG LFT-007 & 2016 & DLF/Lim & $19-5$ & 7.0 & 6.7 & 8.2 & 98 & 92 & 92 & 80 \\
\hline LMG LFT-4450 & 2016 & DLF/Lim & $29-5$ & 8.1 & 7.0 & 8.5 & 97 & 96 & 97 & 95 \\
\hline $100=\ldots$ ton $d s / h a$ & & & & & & & 4.2 & 6.6 & 13.9 & 11.7 \\
\hline
\end{tabular}




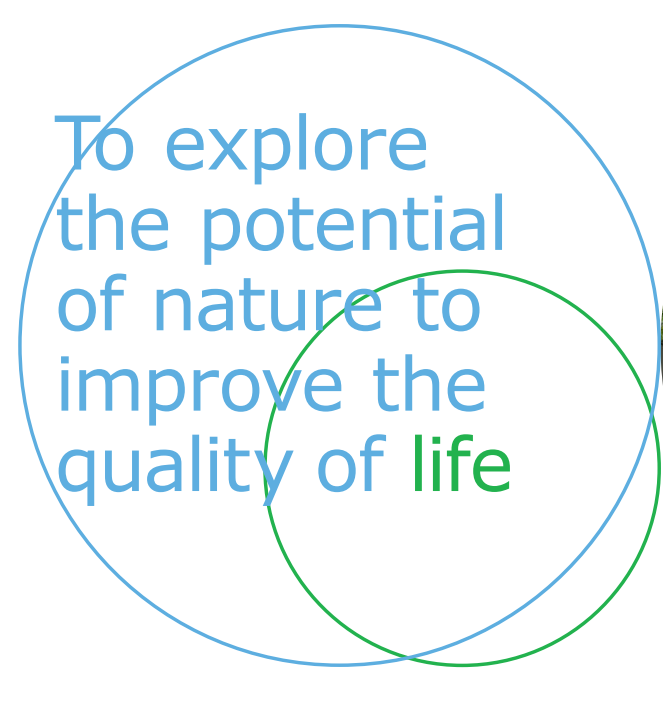

Wageningen Livestock Research Postbus 338

6700 AH Wageningen

T 0317483953

E info.livestockresearch@wur.nl www.wur.nl/livestock-research

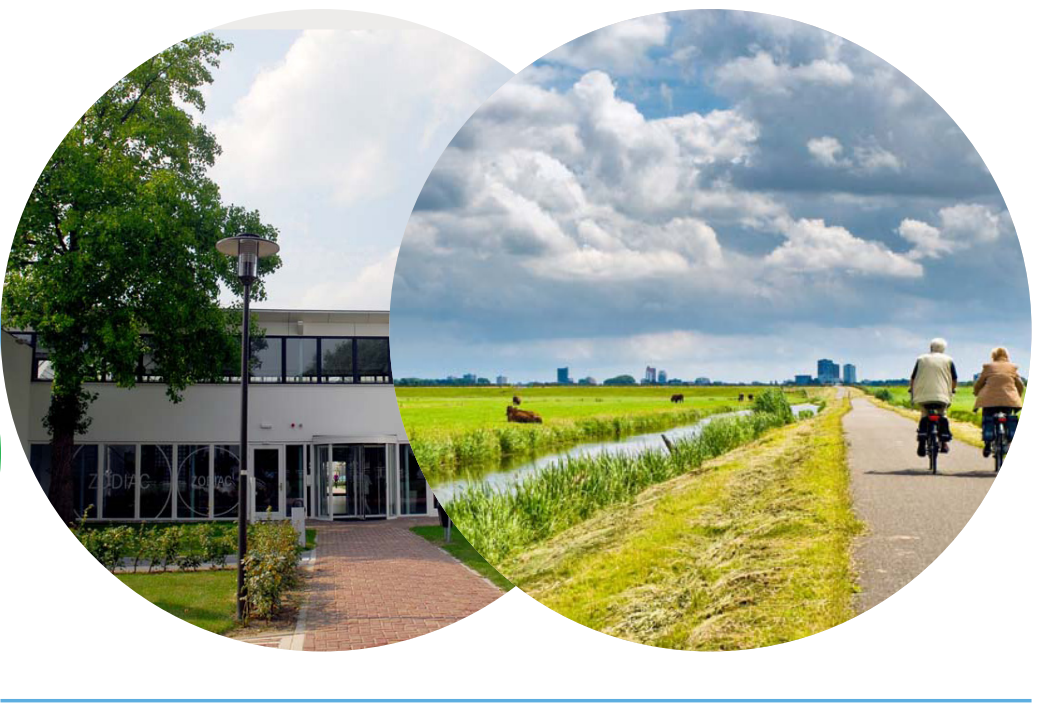

Wageningen Livestock Research ontwikkelt kennis voor een zorgvuldige en renderende veehouderij, vertaalt deze naar praktijkgerichte oplossingen en innovaties, en zorgt voor doorstroming van deze kennis. Onze wetenschappelijke kennis op het gebied van veehouderijsystemen en van voeding, genetica, welzijn en milieu-impact van landbouwhuisdieren integreren we, samen met onze klanten, tot veehouderijconcepten voor de 21 e eeuw.

De missie van Wageningen University \& Research is 'To explore the potential of nature to improve the quality of life'. Binnen Wageningen UR bundelen 9 gespecialiseerde onderzoeksinstituten van stichting DLO en Wageningen University hun krachten om bij te dragen aan de oplossing van belangrijke vragen in het domein van gezonde voeding en leefomgeving. Met ongeveer 30 vestigingen, 6.000 medewerkers en 10.000 studenten behoort Wageningen UR wereldwijd tot de aansprekende kennisinstellingen binnen haar domein. De integrale benadering van de vraagstukken en de samenwerking tussen verschillende disciplines vormen het hart van de unieke Wageningen aanpak. 